\title{
EESTI PEREKONNANIMERAAMATUST
}

\author{
MARJA KALLASMAA, UDO UIBO, PEETER PÄLL
}

$\mathrm{A}$ astal 2016 sai rahastuse algatus koostada analoogiliselt Eesti kohanimeraamatule (edaspidi EKNR) raamat meie perekonnanimedest. Eesti perekonnanimeraamat (EPNR) on kavandatud ülevaatena Eestis pandud perekonnanimedest. 2019. aastal möödub 200 aastat Liivimaa talurahvaseadusest, millega nähti esimest korda ette eestlastele kohustuslik perekonnanimede panemine. Teatav osa eestlasi, näiteks Kanepis ja Vastseliinas, said perekonnanimed juba varem. Perekonnanimede panek tekitas eestlastel uue isikunimede kihi, mida kajastab ka ajuti kasutust leidnud termin liignimi. See kiht tugines aga paljuski olemasolevale nimevarale, eriti lisanimedele-talunimedele ja isanimedele; perekonnanimeks pandi ka ametinimetusi, loodusest lähtuvat sõnavara jm; tulemuseks üsna omanäoline nimistu. Paigutist perekonnanimede võõrkeelsust aitas tasandada 1920.-1930. aastatel aset leidnud perekonnanimede eestistamine, mis muutis nimede keelsuse üldpilti tuntavalt.

Kokkuvõtlik ülevaateteos Eesti perekonnanimedest seni puudub, kuigi on põhjalikke käsitlusi, alates Andrus Saareste 1934. aasta uurimusest „Eesti liignimedest varemalt, nüüd ja tulevikus”, jätkates Edgar Rajandi ning Helmut Tarandi nimeuurimustega 1960.-1970. aastatel (1966 „Perekonnanimedest ja nende uurimise ülesannetest” ning „Meie perekonnanimede liigitamisest ja seletamisest") ning lõpetades Kairit Henno metodoloogiliselt eeskujuliku piirkonnauurimusega „Jaani kihelkonna priinimed” (2000). Väga palju kasulikku sisaldub ajaloolaste, nt Aadu Musta uurimustes (sh 2000 „Eestlaste perekonnaloo allikad”, 2015 „Perekonnaloo uurija käsiraamat”).

Perekonnanimede ainestik on tänapäeval suhteliselt hästi kättesaadav, tänu Rahvusarhiivi digikogule Saaga ja Aadu Musta juhendamisel koostatud andmebaasile OnomastikaNET (eraldi andmed XIX sajandi alguses pandud ning XX sajandil eestistatud nimede kohta). Perekonnanimede sõnaraamatud on ilmunud paljudes maades, sh Hollandis, Leedus, Norras, Saksamaal (mitu eri väljaannet), Šotimaal ja Taanis, Eesti raamatu lähim eeskuju on Soomes välja antud „Sukunimikirja” (Pirjo Mikkonen, Sirkka Paikkala), mis on mitmes eri trükis ilmunud 1984. aastast alates.

Perekonnanimeraamatu projekti on ette valmistatud kaks aastat, idee sündis perioodiliselt toimunud kohanimeraamatu seminaridel, sest perekonnanimede materjal on kohanimedega tihedalt seotud. Nagu kohanimeraamatu projekti puhulgi, kavandatakse perekonnanimeraamat sisuliselt teha mitme asutuse koostöös, sh osaleksid Eesti Keele Instituut, ülikoolide nimeuurijad, Võru Instituut ja pärimusosa koostamisel Eesti Kirjandusmuuseum. Töösse loodetakse kaasata ka genealooge jt.

Raamatu mahuks on kavandatud 6000 märksõna, mis peaks hõlmama neid perekonnanimesid, mille sagedus (nimekandjate arv) Eesti rahvastikuregistri andmeil on 30 ja rohkem. Märksõnastik hõlmab eeskätt Eestis pandud perekonnanimesid, mis tähendab, et sinna satub ka Eestis pandud 
võõrkeelseid perekonnanimesid, kui nende sagedus on 30 ja enam. Täiskujul peaks perekonnanime artikkel sisaldama järgmist teavet: perekonnanimi, sagedus rahvastikuregistris, nime hääldus (välde ja palatalisatsioon), nime käänamine; ajaloolised andmed perekonnanime paneku kohta, sh vanimad registreeringud ja perekonnanime geograafiline lähtepunkt (ainutekkelise nime korral) või algne levimus (mitmetekkelise nime korral); peamised hüpoteesid perekonnanime päritolu/etümoloogia kohta; andmed nime eestistamise vm muutmise kohta; võimaluse korral perekonnanime kohta käiv pärimus ja lõpuks allikaviited. Sissejuhatuses antakse perekonnanimede üldiseloomustus ja senise uurimise ülevaade.

Käesolevas kirjutises ei käsitle me niivõrd teoreetilisi probleeme, kuivõrd esitame tutvustuseks 30 prooviartiklit. Märknime järel on sulgudes nimekandjate arv 2017. aasta alguse seisuga rahvastikuregistri väljavõttes, nimede sagedust 5 ja vähem ei ole isikuandmete kaitse kaalutlustel näidatud. Artikli vormistus püüab üldiselt järgida EKNR-i vormistust ja lühendeid. Artikli päises nime järel on lühikokkuvõte nimepanekukohtadest ( $\mathrm{E}=$ Eestimaa, $\mathrm{L}=$ Liivimaa, S = Setomaa, I = Eesti Ingeri) või -kihtidest (VAN = vanem, enne nimepanekut saadud perekonnanimi, EES = eestistatud perekonnanimi). Lisatud on maakondade (Ha = Harjumaa, Jä = Järvamaa, Lä = Läänemaa, Pä = Pärnumaa, $\mathrm{Sa}=$ Saaremaa, $\mathrm{Ta}=$ Tartumaa, $\mathrm{Va}=$ Valgamaa, $\mathrm{Vi}=$ Virumaa , Vl = Viljandimaa, Võ = Võrumaa) ja kihelkondade lühendid, mõisa nime on tarbe korral mainitud artiklis.

\section{Aigro (196) ['aigro]. L Võ Kan}

Vana-Piigandi mõisas (Kan) pandud ainukordne perekonnanimi (koguduse hingeraamat 1809-1819 Aigro, mõisa hingeloend 1834 Aigro). Kui üldjuhul anti perekonnanimed mõisas ja jõudsid sealt kiriku hingekirja, siis Kanepi kihelkonnas oli vastupidi. Sealne pastor Johann Philipp von Roth (17541818) pani talurahvale perekonnanimed juba enne pärisorjusest vabastamist ning al 1810. a-st on meetrikaraamatus kasutatud tema antud perekonnanimesid. Terve kihelkonna perekonnanimed leiduvad koguduse hingeraamatus 1809-1819. Pastor Rothi antud perekonnanimed on valdavalt eestikeelsed, lihtsad ja napid (Jalg, Kässi, Laud, Leib, Lännik, Warn, Wäits jms). Nende hulgas leidub lõunaeesti murdekeelendeid (Eespäiv 'esmaspäev', Hallap 'halapaju', Kevväi 'kevad', Komitz 'osmik, kuur, kuut, varjualune', Nulk 'nurk', Rattus 'ratsuti', Rügga 'rukis' jt). Ehkki haigur on tänapäeval laialt tuntud linnunimetus, on tegemist Wiedemanni sõnaraamatu põhjal kirjakeelde toodud ja sedakaudu levinud sõnaga, mis on murretes üpris haruldane (XX saj registreeritud toonekure tähenduses üksnes Harglast kujul haigri haigru ja Rõugest kujul haibri). Kanepi on Võru murde põhjapoolseim murrak ja sõnaalgulise $h$ esinemine on ebakindel, mida kajastab ka selle puudumine Aigro nimes. - UU

EAA.1267.1.289:71-73, lk 132, 135-136, 141; EAA.1865.2.18/5:2, 4, 8-10, L 1p-1a, 2p-3, 6p, 7p-9; Must

\section{Albi (33). E Vi Jõh}

Ontika mõisast (Jõh) pärit ainukordne perekonnanimi, mis tugineb varem käibinud lisanimele (1834 Alby Jaan > 1835 Jaan Alby). Nimi viitab suguvõsa esiisa päritolule, kes oli Ontika mõisasse tulnud 1752. a Järvamaalt Albu (sks 
Alp) mõisast. Albi nime on eestistatud üks kord ja asemele valitud lähedase kõlaga Albri (Võhmuta 1939). - UU

EAA.1864.2.IV-3:200, L 193p; EAA.1864.2.VIII-117:370, L 375p-376;

EAA.1864.2.VIII-118:147, L 153p-155; Must

Anvelt (135) <-i〉, [`anv`elt] <-veldi〉, Anveldt <-i〉. L Vl Pil

Kõo mõisast (Pil) lähtuv ainukordne perekonnanimi (1826 Anwelt) on nimeandja omalooming, mille aluseks on Anni Mihkle talu nimi. Viimast kajastab priinime esiosa An-; Anni Tonnise talu pererahvas sai nimeks Annow. Lõpposa -welt (vrd sks Welt 'maailm'), mida kohtab paaris muuski Kõo mõisa nimes (Maimwelt, Truwelt) ning ka mujal pandud nimedes, on pärissaksa perekonnanimedes tavatu. Tõenäoliselt on silmas peetud sõna Feld 'põld', mis on saksa perekonnanimede formandina tavaline. Nime tähendus oleks sel juhul 'Anni põld', mis on vahest ka usutavam kui 'Anni maailm'. Nimede eestistamise ajal on perekonnanimest Anvelt (ühel juhul Anveldt) loobutud 17 korda; asemele valitud nimi algab valdavalt A-tähega (Aaslaid, Aasma, Aasna, Aaste, Aava, Airik, Alas, Allikvee, Andla, Arandi, Avas, Avasalu). - UU

Duden 2005: 818, 926; EAA.1865.3.219/5:2, 42, L 1, 41p-42 jm; Must

Berg (226) 〈-i〉, koh ka P`erk. L Ta Lai, Võ Kan Urv / E Ha Kei, Jä Pee

Pandud kokku kaheksas mõisavallas, sh kolmes Keila khk mõisas ja Naissaarel. Nimi on saksa päritoluga (Berg 'mägi'). Eestistatud on 88 perekonnanime Berg, kusjuures 22 neist said uueks nimeks Pärg ja üks Peri, tõlkevastet mägi sisaldavad võetud nimedest Mäekivi, Mäemets, Mäeorg, Mägist, Aasamäe, Avamägi, Kaldamäe, Kasemägi, Lillemäe, Lillemägi, Pärnamägi, Raidmäe, Uudemäe, Uusmäe. Muud on eripalgelised, tuntuim vast Ariste nimi professor Paul Ariste kaudu. - MK

Must

Daum (45) <-i〉. E Ha Jür, Lä Phl Vig, Vi VJg VMr

Pühalepas on pandud kirikumõisas (1835 Daum), aga kihelkonnas mujal on perekonnanimeks pandud ka Pöial. Vigalas on pandud 1835 Daum mõisatöölisele. Nimi võiks olla tuletatud saksa sõnast Daumen 'pöial'. Daum esineb perekonnanimena ka saksa aladel, kus seda ongi seostatud alamsaksa sõnaga duum 'pöial' lühikasvulise inimese kohta. Nimekuju Daum oleks ülemsaksapärastamine. Eestistamisel on Daum asendatud nimega Tamme. - MK

EAA.1864.2.VIII-84:18, L 17p; EAA.1864.2.VIII-198:3, L 2p;

EAA.1864.2.VIII-134:23, L 23p; EAA.1864.2.VIII-132:102, L 102p; Heintze 1908: 49; Must

\section{Ehala (161). S / EES}

Eesti Vabariigi algusaastail Petserimaal kolm korda võetud perekonnanimi (Järvesuu, Petseri 1921). 51 korda on seda võetud ka perekonnanime eestistamisel, sh 29 juhul E-tähega algava nime asemele. Rohkem kui üks kord on sellega asendatud nimesid Ehrpais Ehrpass (viis korda), Ehrenbusch Ehrenbus (neli korda), Jürgenson (kolm korda), Ehkmann, Ehrmann, Eifel, Einbork, Eltermann, Entson, Gebruk ja Kannika (kaks korda). Omaaegsetes eestistamise soovitusnimestikes puuduv nimi on arvatavasti sündinud paljudel inimestel ühesuguse loogika alusel koidu ja eha vastanduse ning 
Lydia Koidula luuletajanime koosmõjul (koit ja eha > Koidula ja Ehala). UU

EAA.5433.1.15:21-23; Must

\section{Eks $(32)<-i 〉$. E Vi $V N g$}

Unukse mõisas (VNg) pandud ainukordne perekonnanimi (1835 Eks). Selle said 41-aastane Kadri, kes oli tulnud 1832. a naaberkihelkonnast Lüganuselt Saka mõisast, ja tema vähem kui kaheaastane vallaspoeg Jüri. Uudisnimi Eks on moodustatud sõnast eksima ja tähendab siin eksinud naist. Samal põhjusel on Saaremaal perekonnanimeks pandud Eksind (Karja khk Pärsama ms). Eestistamise ajal on nimest Eks loobutud kaks korda, uueks nimeks on valitud Eedla (Laatre 1935) ja Jõekäär (Peningi 1938). - UU EAA.1864.2.VIII-124:5, L 5p-6; EAA.1864.2.VIII-123:14, L 14p-15; Must

Habakuk (63) «-i -e», Habakukk (37) «-kuki -kuke». L Ta Trm, Võ Rõu / E Ha Ris, Lä Vig

Avinurme (Trm) mõisast, Rõuge kirikumõisast, Vihterpalu (Ris) ja Konuvere (Vig) mõisast pärit perekonnanimi (1826, 1835 Abakuck, Abakuk, Habakuk,

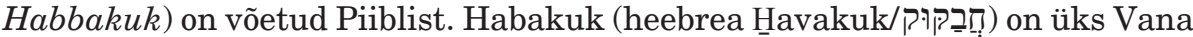
Testamendi prohveteid. Teda peetakse Vanasse Testamenti kuuluva Habakuki raamatu (arvatavasti VII saj eKr) autoriks. Nime tähendus on teadmata. Kõige levinuma käsituse järgi pärineb see akadi keelest, kus habbaqūqu või hambaqūqu tähistas mingit taime (vrd araabia habaq 'basiilik'). Niihästi teise $k$ lisamine eesti nime lõppu kui ka käänamisviis Habakuk(k) : Habakuke on ajendatud rahvaetümoloogilisest arusaamast, et tegu on liitsõnaga, mille järelosa aluseks on linnunimetus $k u k k$. Eestistamise ajal on Habakuki perekonnanimest loobutud seitse korda, asemele on võetud Altjärv, Haaboja, Hiiepalu, Mäeots, Rohtla, Rohtmets ja Saareväli. Viiel juhul on eestistamine toimunud Avinurme vallas. - UU

EAA.1865.5.57:22, L 14p-15; EAA.1865.2.84/4:2, 10, L 1, 10p-11;

EAA.1864.2.VIII-105:130, L 132p; EAA.1865.2.84/4:10, L 137v; Must

\section{Hirtentreu (41) [hirtentr`eu, hirtentr`ei]. E Jä Tür}

Särevere mõisas (Tür) pandud ainukordne perekonnanimi (1835 Hirtentreu; Peetri khk Huuksi ms nimeraamatus mainitud koolmeister Mart Hirtentreu oma perega oli tulnud 1829. a Säreverest). Perekonnanime aluseks on haruldane, saksa vanades vaimulikes lauludes esinev liitsõna Hirtentreu 'karjasetruu' (Hirt 'karjane' + treu 'ustav, truu'), kus karjase all on ilmselt mõeldud vaimset karjast Jeesus Kristust. Perekonnanimi näitab ilmekalt Särevere nimeandja kalduvust taotleda ainulaadset ja erakordset, mida iseloomustavad ka nimed nagu Angelus, Falkenklau, Pärillus, Silwester, Tagobert, Traugott, Wilibold jms. Hirtentreu perekonnanime on eestistatud kaheksa korda. Kolmel juhul on asemele võetud sama tähega algav nimi (Heinpõld, Heinvee, Hintsalu), kahel juhul Üllaste; ühekordsed asendused on Loide, Seljamaa ja Tauga. - UU

EAA.1864.2.VIII-154:222, L 227p-228; EAA.1864.2.VIII-158:295, L 299-300; EAA.1864.2.VIII-159:160, L 159p-160; Must 
Indermitte (34) [indermite]. E Jä Pai

Mäo mõisast (Pai) pärit ainukordne perekonnanimi (1835 InderMitte). Nime aluseks on saksakeelne sõnaühend in der Mitte 'keskel'. Selliseid saksakeelseid asukohamääratlusi leidub Mäo priinimede hulgas mitmeid (AmBach 'jõe ääres', AmEnde 'lõpus', AnderFeld 'põllu ääres', AnderWeide 'karjamaa ääres', ImDorff 'külas'). Perekonnanime Indermitte on eestistatud üks kord ajavahemikus 1919-1935, mil uueks nimeks võeti lõunaeestiline Vastalu, ja hiljem veel kaks korda, kui uus nimi valiti vana nime algustähte silmas pidades (Igalaan 1936 ja Indre 1940). - UU

EAA.1864.2.VIII-157:48, L 48p-49; Must

Iskül (38) [`iskül] <-i〉, Isküll (14) [`isk`üll] 〈-i〉. E Vi Lüg

Pandud Maidla ms Unikülas (1835 Jurg Isküll). 1834 esines Maidla mõisas veel lisanimena (Iskülla M: Jaan, Iskülla oder Wiñi Michli Jürri S: Mart, Iskülla Iürri Iaan). Perekonnanimi Iskül (Isküll) on tõenäoliselt pandud kunagise külanime järgi, ta võib pärineda külanimest Purtse jõe keskjooksul Hirmuse ja Maidla vahel (1465 Iskül, 1796 karjamõis Yskul). 1850 oli Maidla mõisas Hanso Jaan Iskül. Kolm isikut Maidla vallast perekonnanimega Iskül on eestistamisel võtnud uuteks nimedeks Hiiemäe, Ilumäe ja Kalda. - MK EAA.1228.1.478:110, L 182; EAA.1864.2. VIII-121:180, 181, 189, L 178p, 179p, 187p; EAA.1864.2.IX-88:208, L 210p; EKNR

Ivanov (2744) [ivan`off, iv`aanov] 〈-i〉, naiss Ivanova (2853) [ivanoova, iv aanova]. L Ta Kam Puh TMr, Võ Plv / E Ha HJn Kuu, Jä Amb Koe Pee, Lä Kul LNg, Vi Jõh Rak Vai / S / I

Siia on arvatud ka nimekujud Iwanof, Iwanoff, Iwanow, Iwannow. Setumaal 1921 ja Ingeris 1923 kujul Ivanov. Ivanovi aluseks on vene mehenimi Ivan (Иван), kiriklikus pruugis Joann (Иоанн), mille lähteks on kreeka Ioannes

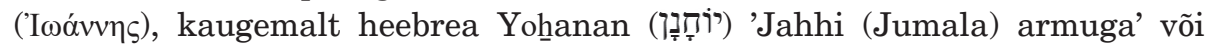

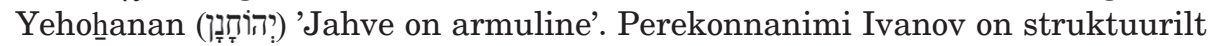
ja ajalooliselt isanimi. Tänu sisserändele oli Ivanov Eestis 1995 sageduselt kuues perekonnanimi, naisvaste Ivanova oli neljandal kohal. Nii et koos võttes kaugelt esimene perekonnanimi Eestis ja on liiga sageli esinevate perekonnanimede nimekirjas, ilma mõjuva põhjuseta ei saa nime Ivanov(a) võtta. Eestistamisel on Ivanovi asemel uus nimi võetud 102 korral, neist 22 on lähtunud nimest Ivanov, ainuüksi Iva 11 korral, peale selle veel Ivala ja Ivalo, Ivas, Iiva Ivandi, Iivandi (3) jne. Ka üks Ivanova on nime muutnud, võttes perekonnanimeks Sirel. Kokku 30 nimevahetajat on valinud I-ga algava uue nime. - MK EAA.5433.1.18:139, 140; Must

Jegorov (496) [jeg`oorov] <-i〉, naiss Jegorova (471) [jeg`oorova]. E Ha HJn / S Algselt Aruküla mõisast (HJn) pärit perekonnanimi (1835 Jegoroff). Põhjasõja ja katku tõttu rahvast hõrenenud Arukülla oli 1730. a asustatud vene talupoegi, kes sajand hiljem said venepärased priinimed. Hiljem on Jegorovi nime kasutatud 1920. a-te algul Petserimaal perekonnanimede panekul (Irboska, Pankjavitsa 1921), Ingerimaal seda ei antud. Perekonnanimi Jegorov oli esialgu mehenimest Jegor (Егор) moodustatud patronüüm (Ivan Jegorov - Ivan Jegori poeg); mehenimi Jegor on kreeka päritoluga nime Georgi (vene Георгий

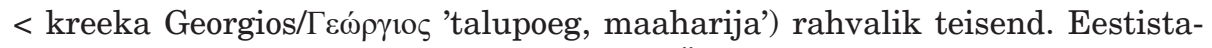
mise ajal loobuti Jegorovi nimest 22 korda. Üheksal juhul säilitati nime algus- 
täht (Jalari, Juurismaa, Jõe, Jõeroo, Jõeste, Jõgever, Jõgis, Järva), ülejäänud juhtudel pole seost eelmise nimega taotletud. Praegune Jegorovite arvukus tugineb hilisemale sisserändele. Aruküla Jegorovite hulgast pärineb maalikunstnik Andrei Jegorov (1878-1954). - UU

EAA.1864.2.VIII-81:27, 32, L 27p-28, 32p-33; EAA.5433.1.18:320-324, L 144148; Must; Unbegaun 1995: 42

Jurkatam (34) [jurkatam] <-i〉, Jurkatamm (10) [jurka`tamm] «-e〉. L Sa Jaa Maasi mõisas on 1833 Jurkatamm, 1834 Johann Jurgatamm, Tönnis Jurgatam, Jurri Jurgatam, Laes Jurgatam = Lahs Jurgatam, Mats Jurgatam $\overline{\text {. Samas }}$ kihelkonnas esines veel Tamm, Tam (Koigi mõisas), Tammberg (Kareda mõisas), Reintam ja Raukentam (Rannaküla mõisas) ning Tam(m)pu(u). Nimeandja on ilmselt kasutanud sõna tamm, tam nimemoodustusliitena. Perekonnanime Jurkatam(m) esiosa on arvatavasti isikunimi. Nimekuju Jurkatam pärineb tõenäoliselt personaalraamatu kirjapildist, kus pikk $m$ oli märgitud ühe tähega, mille peal oli kriips $(\bar{m})$. Kirikuraamatus on Jurkatamm. Vrd Reintam. - MK

EAA.1294.1.114:8, L 7p; EAA.1294.1.277:37; Henno 2000: XXXIV, XLI, XLVIII

Kaelep (71) <-i -a〉. L Pä Aud

Nime Kaelep pole A. Musta andmebaasi järgi kuskil pandud ega selleks ka eestistatud. Audru mõisas on küll pandud ainukordne nimi Kailep, mida tänapäeval sel kujul ei esine. XX saj-l oli Audru khk-s mitu Kaelepa talu, mis väidetavalt olid nime saanud perekonnanime järgi. Ilmselt on perekonnanimes Kailep olev $i$ madaldunud XX saj-ks $e$-ks. Kailep esines Audru Nõmmeste küla lisanimena juba XVII saj lõpul (Kaylep Jack). Lisanime lähtekohaks võis olla mingi loodusnimi, registreeritud on näiteks Kaelepa heinamaa (Mih) ja Kaelepa soo (PJg), Kaelepa-nimeline koht asub Mihkli ja Pärnu-Jaagupi piiril Vee mõisa alal Kõima raba serval vastu Kõima raja (1842 Kaileppa, Kaileppa-Mättik). Nime tähendussisu pole selge, oletada võiks isikunime Kai ja lepp : lepa (või ka järelosise kujunemist sõnast lõpp : lõpe). - MK

EAA.2072.3.35d, L 1; KN; Must; Roslavlev 1977: 9

\section{Karlep (64) <-i〉. E Ha Rap, Vi Iis / EES}

Pandud Iisaku mõisas (1835 Mart Karlep Porskuva, tänapäeva Vaikla küla all), Harjumaal Kuusiku mõisas on pandud Karlepp. Perekonnanimi Karlep ilmus ka 1935. a soovitusnimestikus, selle põhjal on oma võõrapärast nime eestistatud 10 korral, sh Karelson, Karlsbach, Karlson. Kõik eestistajad on säilitanud nimealguse K. Karlep on soovitusnimekirja võinud sattuda kui haruldane perekonnanimi, aga ka kui ürikunimi, nimelt on Padise lääni Rannavakusest kirja pandud XVI saj-l Karilepa küla nimena Karlep. Soovitusnimekirjade koostajaile olid arhivaalid tõenäoliselt tuttavad. Iisaku perekonnanimi Karlep võib pärineda kohanimest, vrd Iisaku endine Karlepi küla (1809 Karlops, 1844 Karlep, 1871 Kaarlöp) ja Karlepa järv (1872-1873 Karleppa Jerw). Selle kohanime seos soovitusnimestikuga pole teada. Vrd Kaarlep, Kaarlõp. - MK

EAA.1.2.934:404, L 400; EAA.1864.2.VIII-118:265, L 263; EAA.1225.2.2:103, L 204; EN; KN; Must; Schmidt 1844; Schmidt 1871 
Kaurla (43) [k`aurla]. E Vi VNg / EES

Algselt Kunda mõisas (VNg) pandud perekonnanimi (1835 Kaurla) lähtub samakujulisest lisanimest. Selle aluseks on mehenimi *Kauril(a) (vrd setu Kauril, isuri Kaurila), mille lähteks on vene Gavriil (Гавриил), rahvapäraselt Gavril (Гаврил) või Gavrila (Гаврила) < kreeka Gabriel $($ Г $\alpha \rho \imath \eta ́ \lambda)<$ heebrea

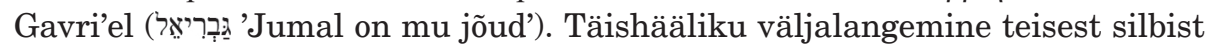
sisekao tõttu (*Kaurila > Kaurla) võimaldab oletada, et nimi on kasutusel olnud juba keskajal (vrd Vassili > Vasli, mis pärineb perekonnanimena samuti Virumaalt). Eestistamise ajal on perekonnanimega Kaurla seitse korda asendatud nime Vospert (Kunda, Kunda-Malla, Narva, Rakvere 1937-1940), mis samuti pärineb Kunda mõisast. Vrd Gabriel, Kaur, Kaurson. - UU

EAA.1864.2.VIII-124:153, 157, 171,L 154, 158p-159, 172p;EAA.1231.1.231:238, lk 479; Saar 2015: 170, 175; Rajandi 1966: 65

Kobrusepa (30) [kobru_sepa]. E Ha Nis

Munalaskme mõisast (Nis) pärinev ainukordne perekonnanimi (1834 Kobbrosерра) lähtub samakujulisest varasemast lisanimest, mille esiosa viitab Kobru küla nimele ja järelosa sepa ametinimetusele. Samast loogikast lähtuvalt on Munalaskmel perekonnanimeks pandud Kobrurätsep (Kobbroretzepp), mis tänapäevaks on hääbunud. Omastava käände vormis perekonnanime Kobrusepa kõrvale on aja jooksul tekkinud nimetava käände vormis Kobrusepp (2017. a üheksa kandjat). - UU

EAA.1864.2.VIII-98:195-196, L 193p-195; EAA.1864.2.VIII-99:84, L 81p-82; EKNR: Kobru; Must

Liivapuu (43) [liiva p $\left.{ }^{\prime} u u\right] . \mathbf{S}$

Eesti Vabariigi algusaastail Petserimaal pandud perekonnanimi (Irboska, Järvesuu, Pankjavitsa, Petseri 1921, Satserinna 1923). Selle aluseks on Vastseliina ja Setu murdesõna liivapuu, mis tähendab ploomipuud (liiva- < vene слива 'ploom'). - UU

EAA.5433.1.25:224-231; VMS: 438

Mutli (78) [m`utli], Mutle (31) [m`utle]. L Vl Vil / EES

Pandud Päri ja Viljandi mõisas (Mutli). Nimi esines Viljandimaal lisanimena 1584 (Muthle Hen nowo) ja 1585-1589 (Mutli Hen). XIX saj on Mutli olnud ka külanimi. Eestistamise käigus on võtnud nime Mutli perekond Muttel, seevastu kaks Mutle perekonda on võtnud uueks nimeks Nurmepaju ja Piirimäe. Mutli nime tähendussisu kohta on raske midagi öelda. Võib-olla on nimi analüüsitav Mut+li. Sõnal mutt on palju tähendusi, nende hulgas loomanimetus ja kalapüügivahendid. Pole kindel, et praegu eestikeelne sõna mutter 'kruvi' oli XVI saj juba saksa keelest laenatud. Usutavaks aluseks nii siinse lisanime kui ka perekonnanime Mutli puhul võiks olla pigem sks Muter 'nõiavitsa või pilda abil veesoone otsija', $r$-i asendumine $l$-iga on mõeldav. Kõige tõenäolisemalt on aga Mutli nimi seotud mulgi sõnaga, millest on $t$-lisi variante läti murretes. Mutli nimes võib olla tekkinud inversioon, mille käigus $t$ ja $l$ on vahetanud kohad. Ka lisanimi Multi esineb Viljandimaal XVI saj. - MK

EKNR; Must; PA IV: 165, 191, 207, 228, 249, 264 
Pandud Varbuse ja Vastse-Nursi mõisas (1826 Nilbe). Setumaal on 1921 pandud nimekuju Nilbõ. Eestistamisel on üks Nilbe võtnud perekonnanimeks Nõmme. Läänemaal Lihula mõisas pandi perekonnanimi Nilb (2017 oli sellenimelisi 16), mis langeb kokku sõna nilv läänemurdelise variandiga. Lisanimena esineb 1601 Viljandimaal Nilpe Han, Pärnumaal Karksis Nilpe Marx. Murretes, eriti Lõuna-Eestis Võrumaal, on nilbe tähendus 'libe', kuid see võib ka juhuslik häälikuline kokkulangevus olla. Vrd Nilp. - MK

EAA.1864.2.VIII-178:24,L24p; EAA.1865.2.64/21:5, L4p; EAA.1865.2.83/13:15, 15p; EAA.5433.1.30:236; EMS; Must; Rev 1601: 116, 140

\section{Nurmik $(228)<-u>$ EES}

Perekonnanimi Nurmik tekkis ja hakkas levima eestistamise tulemusel, kui seda nime on võetud 59 korda. Neist 32 puhul on ilmselt arvestatud seda, et vana ja uus perekonnanimi algaksid sama algustähega. Üks perekonnanime Nurmik populaarsuse põhjusi oli ka see, et soovitud nimi Nurm oli liigsageduse tõttu keelatud ja valiti häälikuliselt lähedane tuletis. Ka otseselt saksapärase (Bedman, Forstmann, Grünberg, Grünvald, Hartmann, Linzbach, Neumann jne) nime vahetajaid oli 32 . Üksikud vahetasid välja oma eesti päritolu ebasoovitavaks peetud nimed (Napp, Neider, Nikker, Nokas, Noll, Näro). Nurmiku vastu vahetati veel mõned arvatavalt moonutatud kirjapildiga nimed (Jets, Jõets) ja isikunimedest sündinud perekonnanimed (Matias, Mikkus, Nuuter jt). Eesti murretes on nurmik teatud puunõu, piimapütt, saartel ja läänemurdes ka teatud taim (vrd ka nurmikas 'Poa', aasnurmikas 'kastehein, Agrostis'), samuti väike ja kängus humalakäbi või õun; nurmikud on 'halvasti kasvanud, ainult lehti ajav juurvili, mugulvili (või kõrsvili)'. Wiedemannil esineb vähendav tuletis sõnast nurm, mida nimevahetajad ilmselt silmas pidasid. Nurmik on esinenud isikunimes XVI saj algul: Mart Nvrmick 1505 Jüri khk-s. Perekonnanime Nurmiks on pandud Läti alal Vidzemes XIX saj. Vrd Nurm. MK

EKMS: I, 40, 43, III, 327, 639, 1117; Johansen 1925: 63; Must; Vaba 2017: 483; VMS; Wd

\section{Oskar (55) [`oskar] 〈-i〉. L Vl Vil / E Ha Kuu, Jä JJn Pee, Vi Kad}

A. Musta andmeil Liivimaa kubermangu ühest (1826 Oskar) ja Eestimaa kubermangu kuuest (1835 Oskar) mõisast pärit perekonnanimi. Liivimaa poolel on seda pandud Viljandimaa ühes mõisas (Vana-Pärsti), Eestimaa poolel Harjumaa kahes mõisas (Kolga, Kõnnu), Järvamaa kolmes mõisas (Metstaguse, Päinurme, Vodja) ning Virumaa ühes mõisas (Vohnja). Oskar (< muinasiiri Oscur, anglosaksi Osgar 'jumala oda') oli XIX saj algul moodne mehenimi. See tuli Euroopas taas käibele James Macphersoni rahvusromantilise luuletsükli „Ossiani laulud” (1760-1765) mõjul, kus Oscar on muistse keldi lauliku Ossiani poeg. Põhjamaades tegi nime tuntuks Rootsi kroonprints, hilisem kuningas Oskar I (1799-1859; troonil 1844-1859); oma endise kindrali pojale oli nime valinud Ossiani lauludest vaimustunud ristiisa Napoleon I isiklikult. Eestlaste hulgas levis Oskar eesnimena alles pärast perekonnanimede panekut ja saavutas XIX-XX saj vahetusel suure populaarsuse. Perekonnanimede panemisel on mõnel juhul lähtutud kõlalähedusest talu nimega, nt Viljandi khk Vana-Pärsti mõisas läks see Oksa tallu. Eestistamise tõttu on Oskari perekonnanimest loobutud 17 juhul. Kümnel juhul on asemele võetud 
sama tähega algav nimi (Ojala, Ojari, Ojasalu, Ojaväli, Oks, Oksaar, Oksaare), seitsmel juhul (Etulaid, Hiiekivi, Kard, Kastan, Lumi, Maidla, Niinsalu) pole seda silmas peetud. - UU

EAA.1864.2.VIII-130:113, L 114p; EAA.1865.3.283/8:3, L 3p; Must; Rajandi 1966: 140; Vilkuna 2003: 174

\section{Pahapill (94) [paha_p ill] <-i〉. L Sa Kaa Mus}

Pandud Elme mõisas (1826 Pahapil) ja Paatsa mõisas (1826 Pahhapil). Eestistamisel on viis perekonda nime Pahapill vahetanud uuteks nimedeks Laine, Pappel, Piirlaid, Tammela ja Toim. Pahapilli aluseks on talu- ja külanimi (1627 Paha Pilli Tönnis, 1798 Pahhapil /talurühm/, 1826 Pahapilli). Kohanimi on kaheosaline, järelosa aluseks on eesnimi Pill, mille lähteks Philippos. - MK

EAA.1865.4.308/2:14, L 26p; EAA.1865.4.340/10:10, L 9p; EKNR; Must

\section{Seppago (30) [s`eppago, sepago]. E Vi VNg}

Kunda mõisas (VNg) pandud ainukordne perekonnanimi (1835 Seppago). Nagu selgub Viru-Nigula koguduse personaalraamatust, tuleneb see Sepa Jaagu lisanimest: Seppago priinime on saanud Seppa Jago p. Josep ja tema pere. - UU

EAA.1864.2.VIII-124:158, L 159p-160; EAA.1231.1.231:235, lk 473

\section{Sulger (34) [s`ulger] «-i〉. E Vi VNg}

Kalvi mõisast (VNg) pärit ainukordne perekonnanimi (1835 Sulger). Karl von Essenile kuulunud Kalvi mõisas on perekonnanimesid mõnel juhul loodud ligikaudu nii, nagu Johannes Aavik lõi sajand hiljem tehissõnu: lisa- ja talunimedes häälikuid suvaliselt ümber paigutades, lisades või välja jättes, nt Retsep (lisanimi) > Trestip (perekonnanimi), Volmer (lisanimi) > Volder, Lermo (perekonnanimed). Sulgeri perekonnanime said Silgo Ado Karel, tema vend Maddis ning nende pered; perekonnanimi on moodustatud lisanimest Silgo (< silk) formandiga -er, kusjuures esisilbi $i$ on suvaliselt asendatud $u$-ga. - UU EAA.1864.2.VIII-124:45，L 45p-46; EAA.1864.2.VIII-123:142，L 141p-142; Must

\section{Tamm (5242) «-e -i〉. L Pä Sa Ta Vl Võ / E Ha Jä Lä Vi / S / I / EES}

Pandud nii Liivimaal kui ka Eestimaal paljudes paikades, kokku 203 mõisavallas, Liivimaal u kaks korda rohkem kui Eestimaal, eriti Tartu- ja Saaremaal, vastavalt 46 ja 32 korral. Setumaal on Tamm pandud 1921, Ingeris 1922. Tamme nimede hulka on arvatud ka variandid Dam, Damm ja Tam. Eestistamisel on võetud uueks nimeks Tamm 17 korral, näiteks ebasobivaks on ilmselt peetud loomanimetustel põhinevaid perekonnanimesid Härg, Oinas, värvinimetust Punane või ka võõrapärasust (Kruhmin, Stamm, Such). Mitu nimevahetajat on otsustanud lühema nimevariandi Tamm kasuks (Jurkatam, Tamme, Tammo, Tamm-Oinas) või on ilmselt taotlenud paremat kõla (Tamp, Timm). Eestistamisel on üks Tamm vahetanud perekonnanimeks Samm, Tam vahetanud perekonnanimeks Tammekand, Damm võtnud nimeks Raid ja perekond Damm nimeks Tamme. Tänapäeval on Tamm levinuim eesti perekonnanimi, mille puhul tähendusliku sisuna on võimalikud eesti puunimetus tamm : tamme või tamm : tammi (vrd sks Damm '(pais)tamm, (raudee)tamm, sõidutee'). Üldiselt seostatakse perekonnanime Tamm eeskätt puunimetusega. 
$\mathrm{Al}$ 2005. a-st on Tamm liiga sagedaste perekonnanimede nimekirjas ja seda ei saa ilma mõjuva põhjuseta uueks nimeks võtta. - MK

EAA.5433.1.42:129, 132; Lisa

\section{Toots (538) $\left[t^{\prime}\right.$ oots, $t$ 'oot's] <-i〉. L Pä Ta Võ / E Ha Vi / EES}

Vaadeldud koos nimevariantidega Tootz, Totz ja Tots. Pandud Liivimaal 24 mõisavallas, Eestimaal kolmes. Eestistamisel on endale perekonnanime Toots võtnud Orik ja Pulk. Liivimaalt on pärit ka perekonnanimi Tootsi, ainsa erandina pandud Järvamaal Koeru khk Ervita mõisas. Perekonnanimed Toots ja Tootsi tulenevad mehenimest Toots. Kagu-Eesti nime Toots puhul tundub õigustatud pilk vene muganditele ja häälikuliselt lähedasele vene isanimele Totševitš (Точевичъ). Praeguse uurimisseisu järgi võiks Toots olla Kagu-Eestile omane nimekuju. Põltsamaa staarostkonnas on 1587 mainitud Thocz Nak uusasukana, ühtlasi näib see olevat esimene Toots staarostkonnas jälgitava aja jooksul. Huvi võiks pakkuda ka sarnane Eesti alal esinenud mehenimi Toos, mis E. Rajandi järgi tuleneb nimest Theodosius või Theodotus. Häälikuliselt võiks Theodotuses teoreetiliselt näha ka üht Tootsi alust, pearõhulise silbi säilimisel Toos $\leftarrow$ Theodosius (vene Феодосий), Toots $\leftarrow$ Theodotus (vene Федот, perekonnanimed Федочев, Федотьев). Paistab, et Kagu-Eestis esines idakristlik Toots, mis sealt levis põhja ja lääne poole. Viljandimaalt on XVI saj-st registreeritud nii Toots, Toos kui ka Toss. (2017 oli 20 isikut perekonnanimega Toos, vrd Holstres 1826 Toos Jaak Tootz S.) Pärnumaale jõudsid nimemugandid täiesti segunenuna XVII-XVIII saj. 1767 on märgitud talupoega Orrametsa Toos. 1788 oli seal Totzi Ado Land 'Tootsi Ado maa', millest tehti karjamõis, tänapäeval Tootsi. Vrd ka teist Pärnumaa kohanime Toosikõnnu (1683 Tosikonna Johans, 1724 Tossikand Jahn). Läänemaa XVI saj vakuraamatus puuduvad eesnimed Toots, Toos ja Toss. Näib, et nimerühm on tulnud Kagu-Eestisse pigem vene mõjul. Vrd Toss. - MK

EAA.1865.3.210/3:88, L 86p; EKNR; Must; Rajandi 1966: 63; Tupikov 1903

Toss (59) [tos's] «-ì, [t’oss] «-u〉. L Sa Muh, Ta Kod MMg San, Vl Hel, Võ Rõu Urv Vas

Pandud Liivimaal üheksas mõisas. Perekonnanime Toss lähtekoht on tõenäoliselt isikunimi Theodosius, mis on Eestisse jõudnud vene mehenime Feodossi (Феодосий) kaudu. Perekonnanimena on registreeritud ka Tosso (16 nimekandjat 2017), pandud samuti Liivimaal Viljandi- (Trv) ja Tartumaal (Kod, Nõo). Vrd Toots. - MK

Must

\section{Üleoja (51) [üle_oja]. E Lä Mär / EES}

Ainukordne nimi, pandud Sõtke mõisas (1835 Ulleoja). Perekonnanimi on saadud talunimest (Sõtke mõisas 1834 Ülleoja Willem, Ülleoja Thomas Sohn Kristjan). Üleoja on ka eestistatud nimedest Baumann (1) ja Überbach (8), viimane nimi on tähenduslikult sama kui eesti Üleoja. Liitsõna üleoja on talupoja lisanimena Pärnumaal esinenud juba XVI saj (Melno Uleoya). - MK EAA.1864.2.VIII-167:301, 302, 311p, 312p; Must; Stackelberg 1928: 164

Toodud prooviartiklid võivad töö käigus täieneda või muutuda. Lahtised või vaieldavad on veel mitmed artikli sisu ja vormistust puudutavad põhimõtted. Näiteks see, kas õnnestub kokku koguda andmed perekonnanime kääna- 
mise ja häälduse kohta, selgub pigem töö käigus, ent katset selleks tehakse. Taotlus on kajastada nimede tegelikku käänamist ja hääldust, st olla kirjeldav, mitte soovitav.

Esialgu on projekt saanud rahastuse kolmeks aastaks (2016-2018), sest rahastav programm „Eesti keel ja kultuurimälu II” lõpeb 2018. aastal, ent tõenäoline on, et töö raamatu kallal kestab sellest kauem. Kui eeldada, et kohanimeraamatu näitel kestab koostamine seitse aastat, siis peaks kogu sõnaraamat valmima 2023. aastaks. Parajasti selleks ajaks, kui saab täis 200 aastat perekonnanimede võtmise algusaastast 1823.

\section{Allikad}

EAA = Rahvusarhiiv. Endise Eesti Ajalooarhiivi fonditähis

EEA.1 Eestimaa rootsiaegne kindralkuberner

EEA.1228 EELK Lüganuse kogudus

EEA.1231 EELK Viru-Nigula kogudus

EEA.1267 EELK Kanepi kogudus

EEA.1294 EELK Jaani kogudus

EEA.1864 Eestimaa kubermangu revisjonilehtede kollektsioon

EEA. 1865 Liivimaa kubermangu revisjonilehtede kollektsioon

EEA.2072 Kaardikogu

EEA.5433 Petserimaa ja Narva-taguste valdade elanike perekonnanimede panemise komisjonid

$\mathrm{KN}$ = Eesti Keele Instituudi kohanimekartoteek

Must = Must, Aadu. Onomastika andmebaas. http://www.ra.ee/apps/onomastika/ index.php/et (3. XI 2017)

\section{Kirjandus}

Duden 2005 = Familiennamen. Herkunft und Bedeutung von 20000 Nachnamen. Bearbeitet von Rosa und Volker Kohlheim. Mannheim-Leipzig-Wien-Zürich: Dudenverlag.

EKMS = Saareste, Andrus 1958-1968. Eesti keele mõisteline sõnaraamat I-IV. Stockholm: Vaba Eesti.

EKNR $=$ Eesti kohanimeraamat. Koost Marja Kallasmaa, Evar Saar, Peeter Päll, Marje Joalaid, Arvis Kiristaja, Enn Ernits, Mariko Faster, Fred Puss, Tiina Laansalu, Marit Alas, Valdek Pall, Marianne Blomqvist, Marge Kuslap, Anželika Šteingolde, Karl Pajusalu, Urmas Sutrop. Toim Peeter Päll, Marja Kallasmaa. Tallinn: Eesti Keele Sihtasutus, 2016.

EMS = Eesti murrete sõnaraamat. Tallinn: Eesti Keele Instituut, 1994-.

EN = Eesti nimi. Valik uusi perekonnanimesid. (Akadeemilise Emakeele Seltsi toimetised XXVII.) Toim Julius Mägiste, Elmar Elisto. Tartu, 1935.

Heintze, Albert 1908. Die deutschen Familiennamen geschichtlich, geographisch, sprachlich. Halle: Buchhandlung des Waisenhauses.

H e n n o, Kairit 2000. Eesti priinimed. Jaani kihelkond. Eesti Keele Sihtasutus, s.l. Johansen, Paul (toim) 1925. Vanem Tallinna Jaani haigemaja vakuraamat. 1435-1507 / Das älteste Wackenbuch des Revaler St. Johannis-Siechenhauses. 
1435-1507. (Tallinna linna arhiivi väljaanded IV (2) / Publikationen aus dem Revaler Stadtarchiv IV (2).) Tallinn: Eestimaa Trükikoda.

Lisa $=$ Regionaalministri 25. veebruari 2005. a määruse nr 8 „Liiga laialdase kasutusega perekonnanimede loetelu kehtestamine" lisa (regionaalministri 06.10.2013. a määruse nr 11 sõnastuses).

Must, Aadu 2000. Eestlaste perekonnaloo allikad. Ajalooarhiiv. Tartu Ülikooli arhiivinduse õppetool. Tartu: Kleio.

M u st, Aadu 2015. Perekonnaloo uurija käsiraamat. Tallinn: Hea Lugu.

PA IV = Polnische Akten IV. 1583-1590. Toim Oleg Roslavlev. Hefte zur Landeskunde Estlands. Heft 6. München, 1973.

Raj andi, Edgar 1966. Raamat nimedest. Tallinn: Eesti Raamat.

R aj a ndi, Edgar, Tar a nd, Helmut 1966. Meie perekonnanimede liigitamisest ja seletamisest. - Keel ja Kirjandus, nr 7, lk 393-402.

R aj andi, Edgar, T a r and, Helmut 1966. Perekonnanimedest ja nende uurimise ülesannetest. - Keel ja Kirjandus, nr 4, lk 226-231.

Rev 1601 = Die Revision Livlands 1601. Estnisches Siedlungsgebiet. Toim Oleg Roslavlev. Hefte zur Landeskunde Estlands. Heft 3. Wolfratshausen-Waldram. München, 1967.

Roslavlev, Oleg 1977. Das Pernauer Land Ende 17. Jh. - Zur Siedlungsgeschichte Estlands. Heft 4. München.

S a a r, Eva 2015. Vene õigeusu eesnimed vadja, isuri ja seto keeles. - Emakeele Seltsi aastaraamat 61 (2015). Tallinn: Emakeele Selts, lk 167-186.

S a a r e s te, Andrus 1935. Eesti liignimedest varemalt, nüüd ja tulevikus. Tallinn: Nimede eestistamise toimkonna kirjastus.

Schmidt 1844 = Generalcharte von Ehstland in 2 Blättern. Mit Unterstützung des Vereins der Merino Zucht zu Orrehhoff. Hrsg. von J. H. Schmidt. [Berlin?] 1844.

Schmidt 1871 = Karte von Ehstland mit den Kreis-, Polizeidistricts- und GutsGrenzen so wie den Plänen der Städte neu umgearbeitet und herausgegeben von Hofrath J. H. Schmidt. [1871, täiend. 1876.]

Stackelberg, Baron F. 1928. Das älteste Wackenbuch der Wiek (1518-1544). Õpetatud Eesti Seltsi aastaraamat / Sitzungsberichte der Gelehrten Estnischen Gesellschaft 1927. Tartu, lk 78-254.

Tupikov 1903 = Словарь древне-русскихъ личныхъ собственныхъ именъ. Трудъ Н. М. Тупикова. С-Петербургъ.

Unbegaun 1995 = Б.-О. Унбегаун, Русские фамилии. Перевод с английского. Москва: Прогресс-Универс.

V a b a, Lembit 2017. Kuidas Liivimaa läti talupojad said endale perekonnanimed - vaade peeglisse. - Keel ja Kirjandus, nr 6, lk 481-485.

Vilkun a, Kustaa 2003. Etunimet. Avustajat Marketa Huitu ja Pirjo Mikkonen. Helsingissä kustannusosakeyhtiö Otava.

VMS = Väike murdesõnastik I-II. Eesti NSV Teaduste Akadeemia Keele ja Kirjanduse Instituut. Tallinn: Valgus, 1982-1989. http://www.eki.ee/dict/vms/ (3. XI 2017).

Wd = Wiedemann, Ferdinand Johann. Eesti-saksa sõnaraamat. Neljas, muutmata trükk teisest, Jakob Hurda redigeeritud väljaandest [1893]. Tallinn: Valgus, 1973. 


\section{On the dictionary of Estonian surnames}

Keywords: onomastics, surnames, dictionaries, etymology

In 2016 a new project was started aiming at compiling a dictionary of Estonian surnames. Most of the Estonian surnames were given in 1826-1834, while a significant part of the surnames were Estonianized in the 1920s and 1930s. The dictionary will comprise about 6000 surnames that are selected based on the frequency of surnames in the Estonian population register (in order to be included the frequency has to be 30 or more) and the availability of historical records (only names given in Estonia will be included). Besides etymology, a surname entry will include data on pronunciation and declension (still subject to discussion), frequency in 2017, data on the giving and change of the surname, original geographical distribution of the name, possible folklore on the naming reasons, and source references. As the study of Estonian surnames has not been as intensive as with place names or even first names, the compilation of the dictionary must involve a lot of research. As an example, 30 name entries are presented for further feedback.

Marja Kallasmaa (b. 1950), PhD, Institute of the Estonian Language, Senior Lexicographer,marja.kallasmaa@eki.ee

Udo Uibo (b. 1956), Institute of the Estonian Language, Senior Lexicographer, udo.uibo@eki.ee

Peeter Päll (b. 1961), PhD, Institute of the Estonian Language, Head of Language Planning, peeter.pall@eki.ee 